\title{
PREPARATION AND IN-VITRO EVALUATION OF SUSTAINED RELEASE THEOPHYLLINE MICRO- SPHERES
}

\author{
W. S. Sakran
}

Department of Pharmaceutics, Faculty of Pharmacy, October 6 University, Giza, Egypt

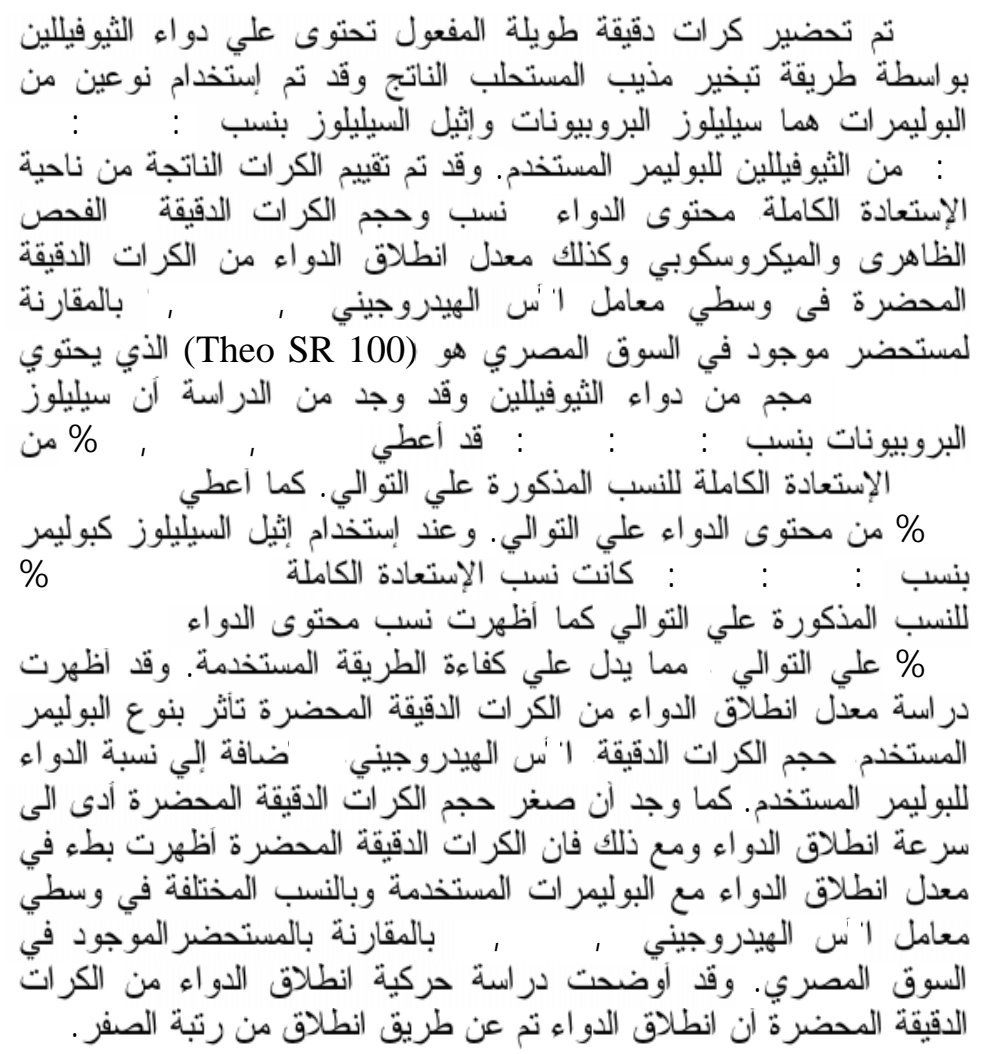

A modified emulsion-solvent evaporation technique was utilized to prepare sustained release microspheres containing theophylline (TH). Two polymers were used for microspheres preparation, namely cellulose propionate $(C P)$ and ethyl cellulose (EC). The two polymers were used at 1:1, 2:1, and 3:2 (drug - polymer ratios).

Received in 14/3/2009, Received in revised form in 26/4/2009 \& Accepted in 27/4/2009 
The prepared microspheres were evaluated for their total recovery, drug loading, particle size distribution, surface morphology, drug content and drug release rate characteristics. The results have shown that, the total percentages drug recovery reached 96, 97.7and 90.3 for cellulose propionate at 1:1, 2:1 and 3:2 (drug polymer ratios), and that of drug loading reached 89, 90, and 92 respectively. However, with ethyl cellulose, the total \% drug recovery reached 99, 100, and 94 using the same drug - polymer ratios, and the total \% drug loading reached, 85, 90, and 90 respectively. The results obtained have shown a significant complete recovery with an excellent drug loading and thus the efficiency of the procedure utilized to encapsulate the drug. The drug release characteristics from the prepared microspheres in simulated gastric fluid ( $p H$ 1.2) and phosphate buffer ( $p H$ 6.8) were compared with commercial sustained release capsules of theophylline (Theo SR 100). Results have revealed that, the release rate of theophylline was influenced by the type of polymer, microsphere size, $p H$ as well as drug to polymer ratio. The decrease in particle size of the prepared microspheres led to increase in the release rate. However, the prepared microspheres showed more retarded release of theophylline than from the tested commercial product. Moreover, ethyl cellulose as a polymer was more effective for sustained effect. The release data were fitted to Peppas diffusion equation. Results have indicated that the release pattern of theophylline followed zero-order kinetics.

\section{INTRODUCTION}

Microencapsulation is a process by which a gas, liquid, or solid material (core) is packaged inside micronized capsule of a second material (shell) ${ }^{1}$. The process embodies a series of techniques for the entrapment of solids or liquids within polymer coats or matrices. It has been used for the improvement of drug stability, taste masking, providing sustained release, and for producing targetable drug carriers ${ }^{2 \& 3}$. Microencapsulation by emulsification / solvent evaporation technique is conceptually a simple procedure. This technique can be tailored to produce microspheres over a wide size range, and by choice of suitable solvent systems, many drugs with different solubility characters can be encapsulated $^{4-6}$. The structure of microspheres produced by emulsification / evaporation is essentially drug dispersed through a matrix as a solid or a molecular dispersion ${ }^{7-9}$. Oral sustained release preparations can be classified into multiple-unit preparations and single-unit preparations. Multiple-unit preparations distribute granules relatively widely 
in the digestive tract after administration and have been reported to be relatively unaffected by gastric emptying rate, increase in bioavailability, and less variation in the results of pharmacokinetic studies ${ }^{10-13}$. Theophylline has long been used as a treatment of bronchial asthma ${ }^{14}$. It has a relatively short half-life and narrow therapeutic index, with 5-20 $\mu \mathrm{g} / \mathrm{ml}$ serum concentrations. The desirability of maintaining theophylline plasma levels have led to the development of sustained release formulations. Thus sustained-release formulations that can produce more uniform serum concentrations with less fluctuation in peak-trough levels are useful for the oral delivery of theophylline. In addition, sustained release theophylline formulations can ensure good patient compliance since it is difficult for a patient to take oral medication repeatedly during an acute asthma attack ${ }^{15-23}$. Hence the objective of this study aims to encapsulate theophylline using enhanced emulsion-solvent evaporation process for the rapid and efficient microencapsulation. Commercial slow release theophylline capsules were used for in-vitro comparison of drug release.

\section{MATERIALS AND METHODS}

\section{Materials}

Theophylline, ethyl cellulose, and cellulose propionate (Sigma Chemical Co. St.Louis, MO, United States), liquid paraffin (S\&C Chem.,
Germany). All other reagents and chemicals were of analytical grades. Theo SR 100; commercial sustained release theophylline capsules produced by gsk GlaxoSmithKline (Cairo, Egypt). The product was used as a reference for in-vitro drug release.

\section{Apparatus}

Mechanical mixer (ER10, MLW, Germany), pH meter (Hanna pH213), electron scanning microscope (Jeol, JSM-5400 LV, Japan), set of standard sieves (Gilson Company SS-15, USA), double beam spectrophotometer (Shimadzu UV-1601PC, Japan), dissolution apparatus USP 20 type II (Pharmatest Germany).

\section{Methods \\ Preparation of theophylline microspheres}

Theophylline microspheres were prepared by utilizing a modified emulsion/solvent technique ${ }^{23 \& 24}$. The polymer was dissolved in acetone and various amounts of the drug was added to the polymer solution to produce $1: 1,2: 1$, and $3: 2$ drug to polymer ratios. The mixture was emulsified into $100 \mathrm{ml}$ liquid paraffin at $600 \mathrm{rpm}$ for $2 \mathrm{hrs}$ at room temperature, and then the emulsification temperature was raised to $40^{\circ} \mathrm{C}$ on water bath to complete acetone evaporation. The formed microspheres were separated, washed three times with n-hexane to remove any adsorbed mineral oil and collected by filtration. The microspheres were then dried at room temperature. 


\section{Calculation of the total recovery}

The percentage total recovery was determined by the following equation:

$\%$ Recovery $=$

Weight of collectedmicrospheres $\frac{\text { total weight of drug and polymerused }}{100}$

\section{Drug loading}

A weighed amount of microspheres equivalent to $50 \mathrm{mg}$ theophylline was extracted with the dissolution medium after dissolving the polymer with $5 \mathrm{ml}$ ethyl acetate. Drug concentration was determined after filtration spectrophotometrically at $272 \mathrm{~nm}$ wavelength ${ }^{23}$. At the specified wavelength, no spectrophotometric interferences were observed from blank microspheres.

\section{Determination of surface charac- teristics of the prepared micro- spheres.}

The surface characteristics of the prepared microspheres were observed with a scanning electron microscope.

\section{Determination of particle size range (sieve analysis)}

Microspheres size distribution was determined by using a set of standard sieves (USP) and the following size ranges were determined: $1500-1000$ $\mu \mathrm{m}, 1000-500 \mu \mathrm{m}, 500-355 \mu \mathrm{m}, 355-$ $250 \mu \mathrm{m}$, and $250-180 \mu \mathrm{m}$.

\section{In-vitro drug release characteristics}

In-vitro release studies of theophylline from the prepared microspheres were carried out using USP dissolution apparatus II.
Accurately weighed amounts of the dried microsphere equivalent to 50 $\mathrm{mg}$ theophylline were suspended in $900 \mathrm{ml}$ of dissolution media at $37^{\circ} \mathrm{C}$ and $100 \mathrm{rpm}$. The dissolution media used were simulated gastric fluid $(\mathrm{pH}$ 1.2) and phosphate buffer ( $\mathrm{pH} 6.8)$. At specified time intervals, $5 \mathrm{ml}$ of dissolution fluid was withdrawn to assay the released drug spectrophotometrically at $272 \mathrm{~nm}$ and replaced by $5 \mathrm{ml}$ of fresh medium. Each graphical data point was an average of three determinations. Corrections were made for the removal of samples.

\section{Release study of theophylline from commercial theophylline product}

The commercial theophylline product (Theo SR), each capsule containing $100 \mathrm{mg}$ of theophylline was used as a reference for in-vitro drug release study. The release also was carried out in both $\mathrm{pH} 1.2$ and pH 6.8.

\section{Kinetic Studies of drug release}

To investigate the mechanism of drug release from the prepared microspheres and commercial product, the release data were fitted to the following mathematical equation developed by Ritger and Peppas ${ }^{24-26}$.

$\mathrm{Q}=\mathrm{k} \mathrm{t}^{\mathrm{n}} \quad$ (equation 1$)$

By taking the log scale

$\log \mathrm{Q}=\log \mathrm{k}+\mathrm{n} \log \mathrm{t} \quad$ (equation 2)

where $\mathrm{Q}$ is the fractional drug released at time $\mathrm{t}, \mathrm{k}$ is a kinetic constant and $\mathrm{n}$ is an exponent indicative of the release mechanism. 
When $\mathrm{n}$ approximates $0.5, \quad \mathrm{a}$ Fickian/diffusion controlled mechanism is implied, with $0.5<\mathrm{n}<1$ indicating non Fickian transport, and $\mathrm{n}=1$ for zero order release mechanism.

\section{RESULTS AND DISCUSSION}

\section{Size distribution of the prepared microspheres}

Figure $1(\mathrm{~A} \& \mathrm{~B})$ shows the size distribution (histograms) of the prepared microspheres of theophylline with cellulose propionate and ethyl cellulose respectively at $1: 1$, $2: 1$, and $3: 2$ drugs to polymer ratios. The obtained microspheres with size ranges of $1500-1000 \mu \mathrm{m}$ and1000$500 \mu \mathrm{m}$ were used to demonstrate the release characteristics of theophylline.

\section{Scanning electron microscopy}

Figure 2 shows the scanning electron micrographs of theophylline microspheres prepared with cellulose propionate at 1: 1 drug to polymer ratio. The prepared microspheres were spherical, showing few pores on their surfaces due to rapid evaporation of the organic solvent.

\section{Total percentage drug recovery}

The Total $\%$ drug recovery values reached 96, 97.7 and 90.3 from theophylline microspheres prepared with cellulose propionate at 1:1, 2:1 and 3:2 (drug - polymer ratios) respectively. However, when ethyl cellulose was used as a polymer in microspheres preparation, the total \% drug recovery reached 99,100 and 94 respectively using the same drugpolymer ratios (Fig. 1A\&B). The results obtained show complete recovery and thus the efficiency of the procedure used to encapsulate the drug.

Figure $1(A \& B)$ also shows that the particle size of the prepared microspheres was influenced by polymer type and concentration. The obtained results are in agreement with Mohammed and $\mathrm{Hassan}^{24}$. The authors have found that the particle size of the prepared microspheres of ciprofloxacin and nor-floxacin with cellulose acetate were increased with polymer concentration.

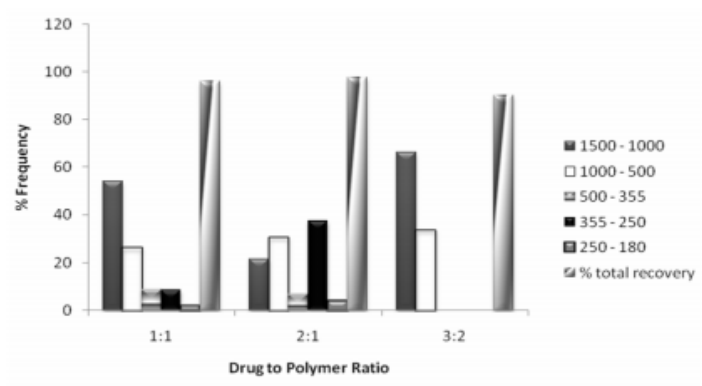

Fig. 1A: Effect of drug to polymer ratio on the percent frequency size distribution and percent recovery of theophylline microspheres prepared using cellulose propionate.

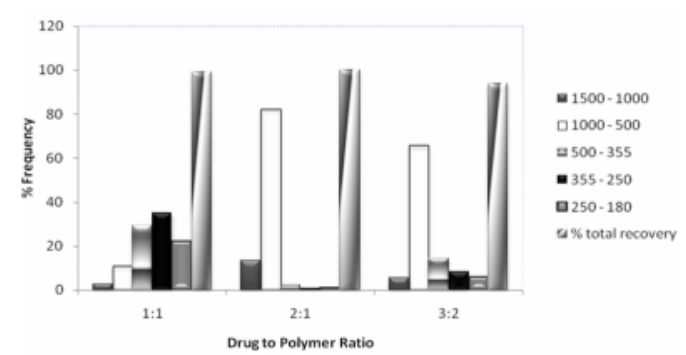

Fig. 1B: Effect of drug to polymer ratio on the percent frequency size distribution and percent recovery of theophylline microspheres prepared using ethyl cellulose. 

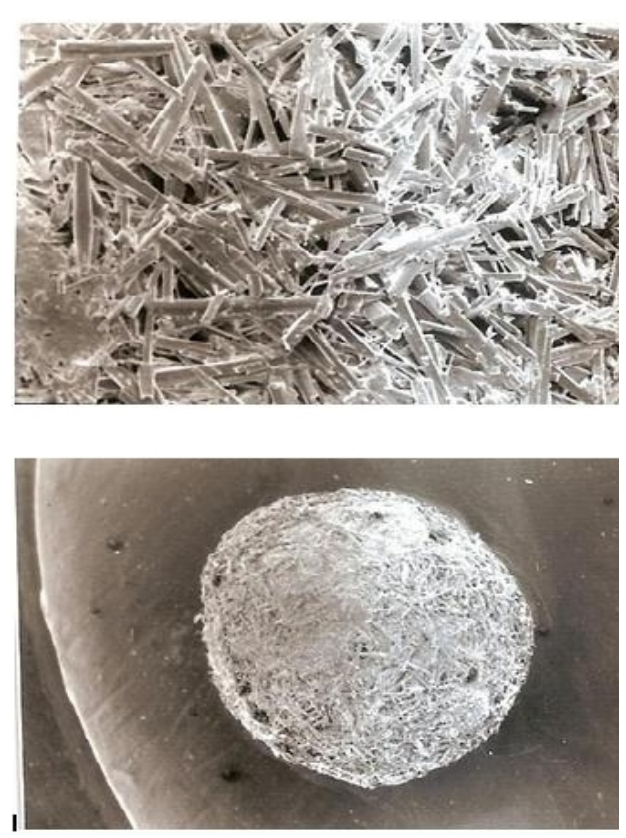

Fig. 2: Scanning electron micrograph of theophylline microspheres prepared with cellulose propionate (1:1) drug to polymer ratio. (Up): high magnification, (down): low magnification.

Percentage drug loading of the prepared microspheres

The $\%$ drug loading reached 89 , 90 and 92 for theophylline microspheres prepared with cellulose propionate at 1:1,2:1 and 3:2 (drug polymer ratios) respectively. However, the corresponding $\%$ drug loading reached 85,90 , and 90 for theophylline microspheres prepared with ethyl cellulose at the same drug polymer ratios respectively. These findings indicate excellent drug loading.
Drug release studies of the prepared microsphere and commercial (Theo SR 100)

Effect of microspheres size on theophylline release

Figure $3(\mathrm{~A}-\mathrm{C})$ and figure $4(\mathrm{~A}-\mathrm{C})$ show the effect of particle size on theophylline release from the prepared microspheres using cellulose propionate with different ratios in $(\mathrm{pH}$ 1.2) and ( $\mathrm{pH} 6.8)$ respectively. The results obtained reveal that the release rate of theophylline was markedly retarded with microspheres prepared with cellulose propionate (3:2) drug to polymer ratio with size range 1500 $1000 \mu \mathrm{m}$ in both $\mathrm{pH}$ values compared with commercial product (Theo SR 100). The relatively rapid release from the smaller microspheres size range 1000-500 $\mu \mathrm{m}$ when compared with larger microspheres could be attributed to the larger surface area of the smaller microspheres, which is in agreement with Mohammed and Hassan $^{24}$. In addition, figure 5 (A\&B) show the effect of particle size on theophylline release from the prepared microspheres prepared with ethyl cellulose (2:1) drug - polymer ratio in $(\mathrm{pH}$ 1.2) and $(\mathrm{pH}$ 6.8) respectively compared with commercial (Theo SR 100). The results illustrate similar effects obtained with cellulose propionate, i.e., the prepared microspheres showed a retarded release profiles and the smaller particles show a relatively rapid release than lager microspheres due to available lager surface area ${ }^{24}$. 


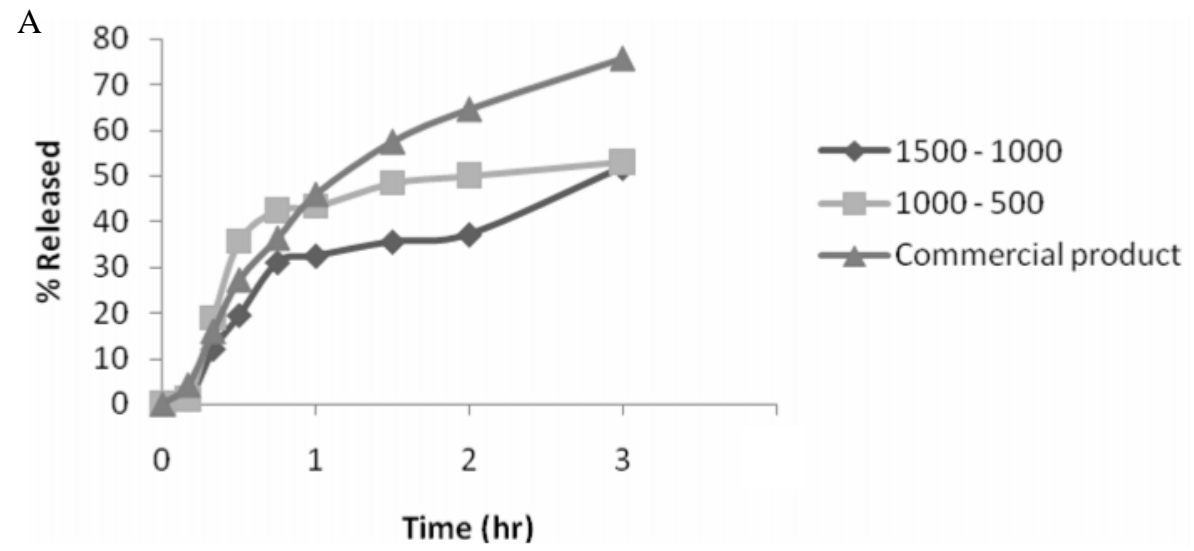

B
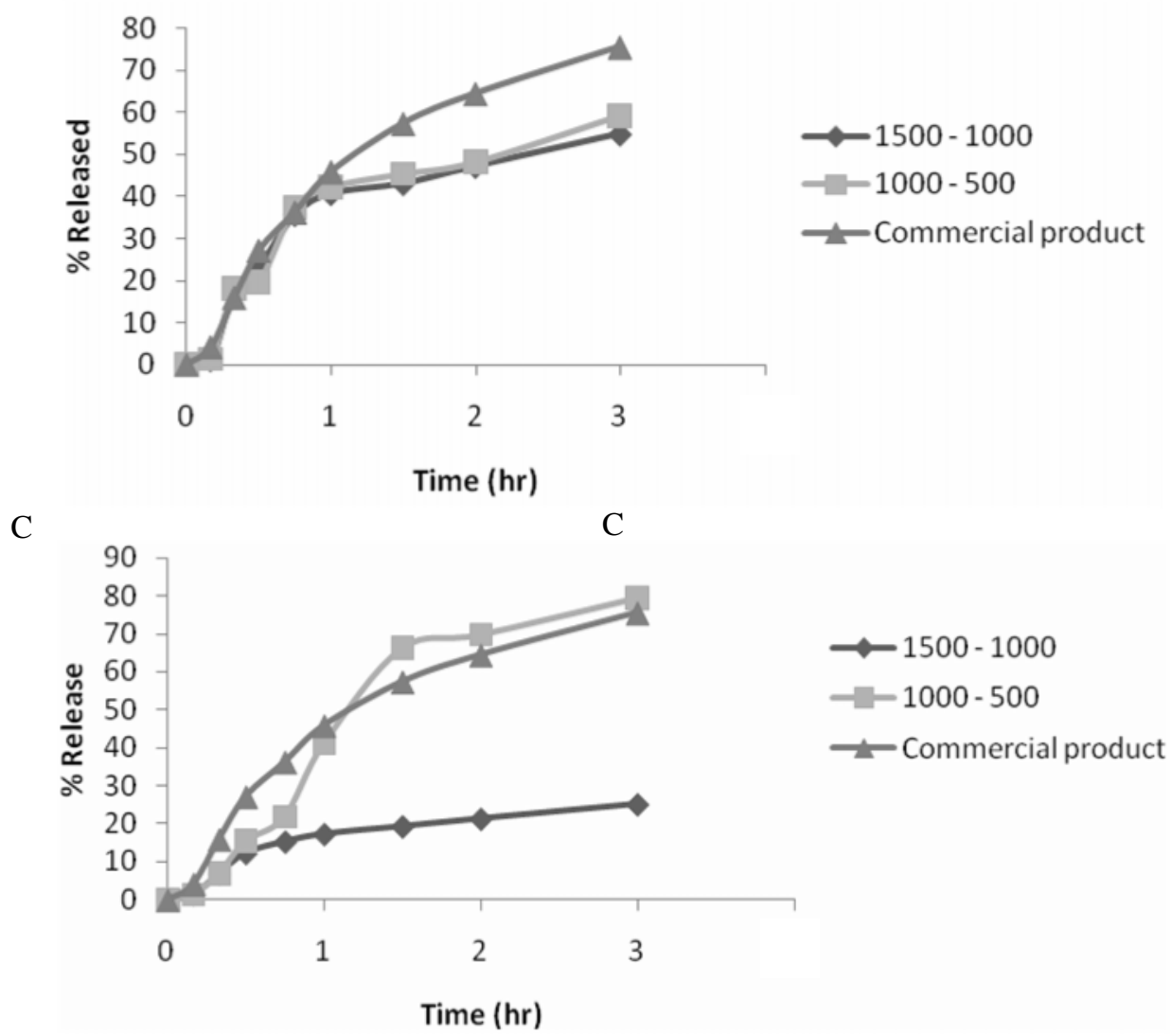

Fig. 3: Effect of particle size on theophylline release from microspheres prepared with cellulose propionate $\mathrm{pH} 1.2$ compared with the commercial product, (A) $1: 1$, (B) $2: 1$ and (C) $3: 2$. 
A

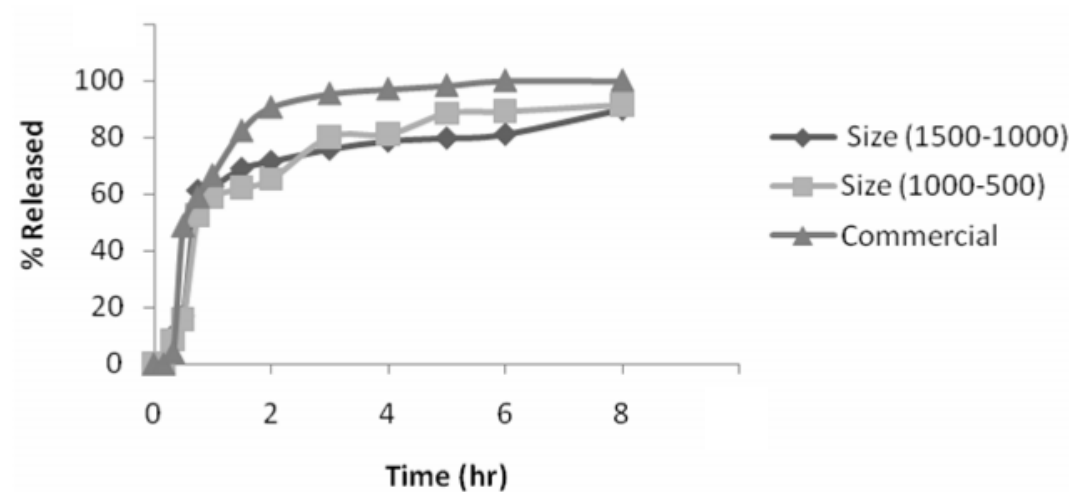

B

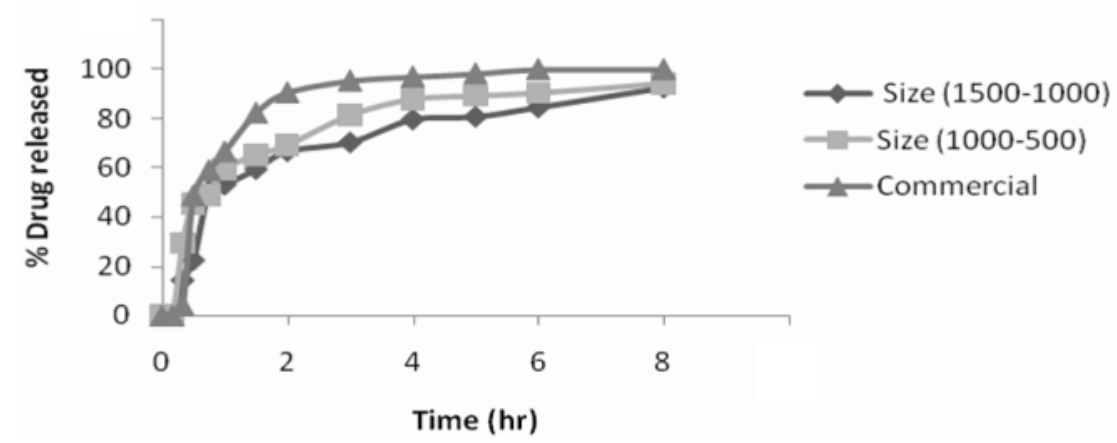

C

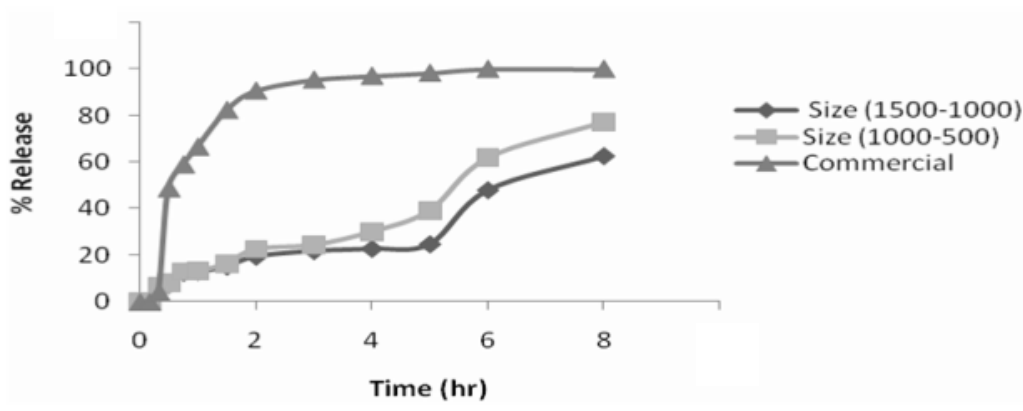

Fig. 4: Effect of particle size on theophylline release from microspheres prepared with cellulose propionate $\mathrm{pH} 6.8$ compared with the commercial product, (A):1:1, (B):2:1 and (C):3:2. 


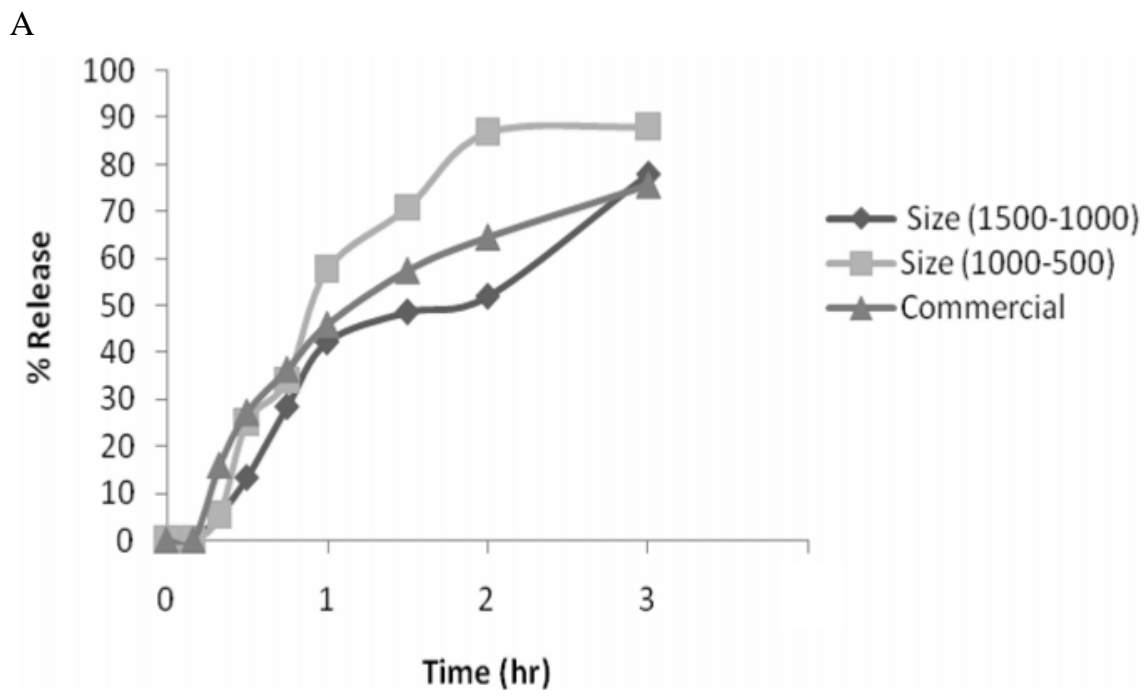

B

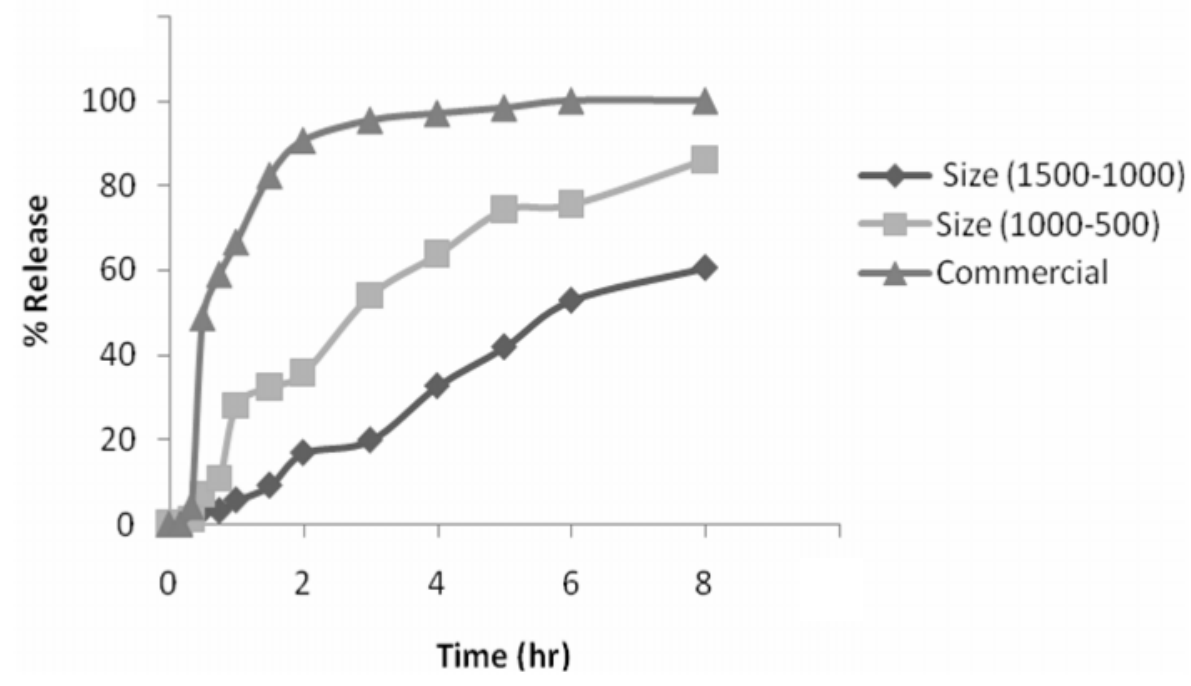

Fig. 5: Effect of particle size on theophylline release from microspheres prepared with ethyl cellulose (2:1) compared with the commercial product, (A) $\mathrm{pH} 1.2$ and (B) $\mathrm{pH} 6.8$. 
Effect of drug to polymer ratio on theophylline release

Figure $6(A \& B)$ shows the effect of drug to polymer ratio on theophylline release from the prepared microspheres prepared with cellulose propionate and ethyl cellulose respectively in $\mathrm{pH} 1.2$ compared with the commercial product (Theo SR 100). The microspheres with size range $1000-500 \mu \mathrm{m}$ were selected to study this effect. The results reveal that, the release profiles from both microspheres prepared with cellulose propionate and ethyl cellulose (1:1) drug to polymer ratio show the most retarded release patterns when compared with the commercial product (Theo SR 100). Moreover, this effect was more with microspheres prepared with ethyl cellulose.

A

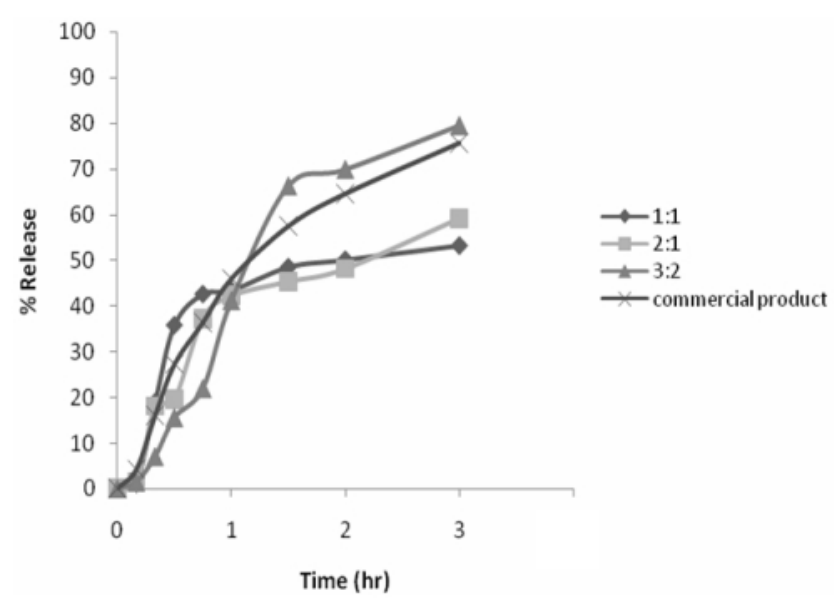

B

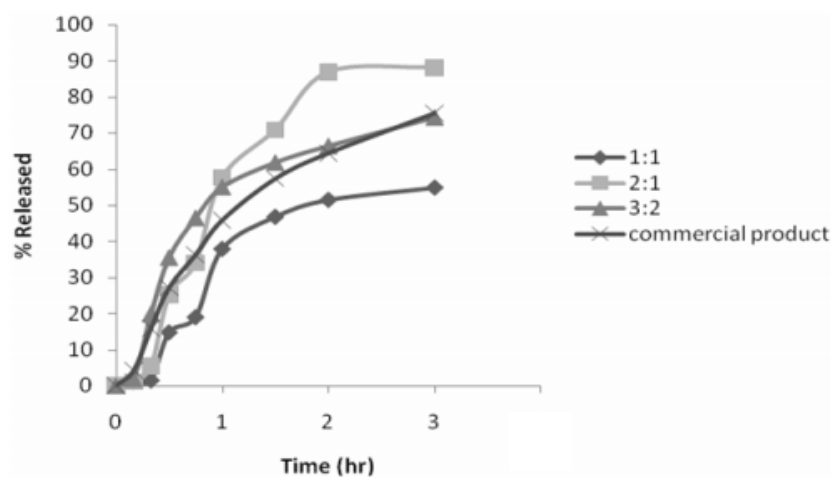

Fig. 6: Effect of drug to polymer ratio on theophylline release from microspheres prepared with (A) cellulose propionate and (B) ethyl cellulose (P.S 1000 $500 \mu \mathrm{m}) \mathrm{pH} 1.2$ compared with the commercial product. 
Effect of $\mathbf{p H}$ on theophylline release

Figure 7 (A\&B) shows the release profiles of theophylline from microspheres prepared with cellulose propionate (Fig. 7A) and ethyl cellulose (Fig. 7B) respectively. This study was carried out using microspheres prepared in ratio $(1: 1)$ drug to polymer ratio with $1000-500$ $\mu \mathrm{m}$ size range. The data reveal that the prepared microspheres show retarded release of the drug compared to that from the commercial product (Theo SR 100) in both $\mathrm{pH}$ values (1.2 and 6.8). This may indicate that the use of the prepared microspheres could control the release of the drug. Moreover, ethyl cellulose when used as a polymer show more retardation effect than cellulose propionate (Fig. $7 \mathrm{~A} \& \mathrm{~B})$.

A

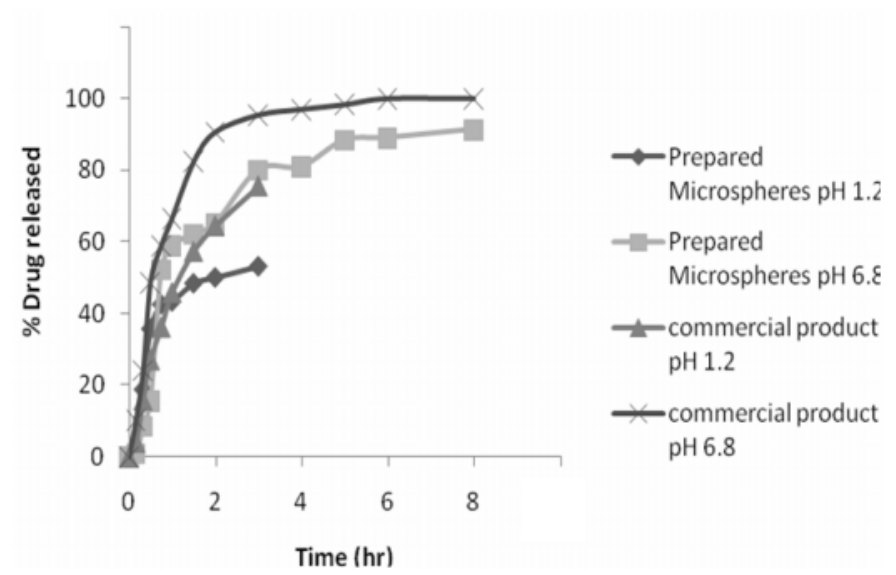

B
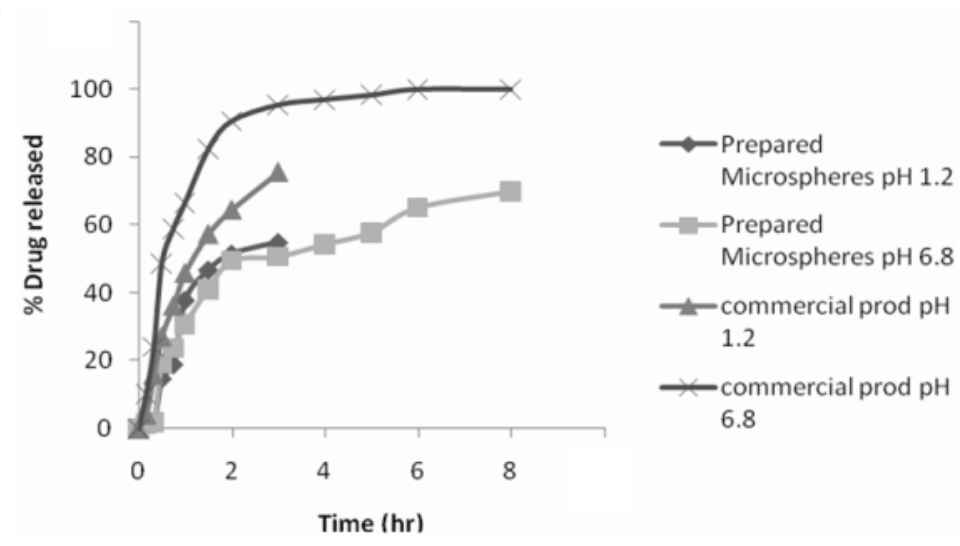

Fig. 7: Effect of $\mathrm{pH}$ on release of theophylline from microsphere prepared with (A) cellulose propionate and (B) ethyl cellulose (1:1) particle size (1000-500 $\mu \mathrm{m})$ in comparison with the commercial product. 


\section{Release kinetics}

Tables (1A and 1B) show the kinetic parameters obtained from fitting the release data of theophylline microspheres prepared with cellulose propionate and ethyl cellulose respectively to the Ritger and Peppas kinetic equation ${ }^{24-26}$. It is evident that the fitting curves are almost linear, as indicated by the higher linear correlation coefficient (r) and determination coefficient $\left(\mathrm{r}^{2}\right)$ values, which reached almost $>0.9$ (table $1 \mathrm{~A}$ and 1B). The $\mathrm{n}$ values approach 1 indicting zero order release mechanism of theophylline from the prepared microspheres ${ }^{24-26}$. However, the $n$ values of the commercial capsules reported 0.633 and 0.799 in $\mathrm{pH}(6.8)$ and $\mathrm{pH}$ (1.2) respectively are an indication to a non-Fickian transport mechanism of theophylline release from the commercial capsules.

Table 1A:kinetic parameters of the release data of theophylline microspheres prepared with cellulose propionate compared to the commercial product.

\begin{tabular}{|c|c|c|c|c|c|c|}
\hline \multirow{2}{*}{$\mathrm{pH}$} & \multirow{2}{*}{$\begin{array}{c}\text { Particle size } \\
(\mu \mathrm{m})\end{array}$} & \multirow{2}{*}{$\begin{array}{c}\text { Drug: polymer } \\
\text { ratio } \\
\end{array}$} & \multicolumn{4}{|c|}{ Kinetic parameters } \\
\hline & & & $\mathrm{r}$ & $\mathrm{r}^{2}$ & $\mathrm{~K}$ & $\mathrm{n}$ \\
\hline \multirow{6}{*}{6.8} & \multirow{3}{*}{$1500-1000$} & $1: 1$ & 0.835 & 0.698 & 26.13 & 0.911 \\
\hline & & $2: 1$ & 0.840 & 0.710 & 27.11 & 0.855 \\
\hline & & $3: 2$ & 0.955 & 0.911 & 11.02 & 0.737 \\
\hline & \multirow{3}{*}{$1000-500$} & $1: 1$ & 0.857 & 0.736 & 24.96 & 0.969 \\
\hline & & $2: 1$ & 0.710 & 0.510 & 224.56 & 1.060 \\
\hline & & $3: 2$ & 0.976 & 0.953 & 12.48 & 0.800 \\
\hline \multirow{6}{*}{1.2} & \multirow{3}{*}{$1500-1000$} & $1: 1$ & 0.883 & 0.779 & 24.57 & 1.050 \\
\hline & & $2: 1$ & 0.846 & 0.710 & 28.98 & 1.110 \\
\hline & & $3: 2$ & 0.906 & 0.821 & 13.80 & 0.858 \\
\hline & \multirow{3}{*}{$1000-500$} & $1: 1$ & 0.803 & 0.646 & 32.01 & 1.104 \\
\hline & & $2: 1$ & 0.869 & 0.755 & 28.74 & 1.070 \\
\hline & & $3: 2$ & 0.968 & 0.937 & 29.36 & 1.170 \\
\hline$* 6.8$ & & & 0.842 & 0.709 & 36.00 & 0.633 \\
\hline$* 1.2$ & & & 0.728 & 0.529 & 24.00 & 0.799 \\
\hline
\end{tabular}

*Data of the commercial capsules. 
Table 1B: kinetic parameters of the release data of theophylline microspheres prepared with ethyl cellulose.

\begin{tabular}{|c|c|c|c|c|c|c|}
\hline \multirow{2}{*}{$\mathrm{pH}$} & \multirow{2}{*}{$\begin{array}{c}\text { Particle size } \\
(\mu \mathrm{m})\end{array}$} & \multirow{2}{*}{$\begin{array}{c}\text { Drug: polymer } \\
\text { ratio } \\
\end{array}$} & \multicolumn{4}{|c|}{ Kinetic parameters } \\
\hline & & & $\mathrm{r}$ & $r^{2}$ & $\mathrm{~K}$ & $\mathrm{n}$ \\
\hline \multirow{6}{*}{6.8} & \multirow{3}{*}{$1500-1000$} & $1: 1$ & $*$ & $*$ & $*$ & $*$ \\
\hline & & $2: 1$ & 0.990 & 0.982 & 6.618 & 1.091 \\
\hline & & $3: 2$ & 0.977 & 0.955 & 8.595 & 1.291 \\
\hline & \multirow{3}{*}{$1000-500$} & $1: 1$ & 0.887 & 0.786 & 16.78 & 0.939 \\
\hline & & $2: 1$ & 0.990 & 0.982 & 6.61 & 1.091 \\
\hline & & $3: 2$ & 0.984 & 0.968 & 5.537 & 1.247 \\
\hline \multirow{6}{*}{1.2} & \multirow{3}{*}{$1500-1000$} & $1: 1$ & $*$ & $*$ & $*$ & $*$ \\
\hline & & $2: 1$ & 0.946 & 0.896 & 25.41 & 1.501 \\
\hline & & $3: 2$ & 0.936 & 0.877 & 27.58 & 1.122 \\
\hline & \multirow{3}{*}{$1000-500$} & $1: 1$ & 0.931 & 0.866 & 20.05 & 1.516 \\
\hline & & $2: 1$ & 0.936 & 0.8 .77 & 34.65 & 1.519 \\
\hline & & $3: 2$ & 0.936 & 0.877 & 27.58 & 1.122 \\
\hline
\end{tabular}

*Not used for release studies because too small amounts obtained with this size range.

\section{Conclusion}

Controlled release microspheres of theophylline were successfully prepared utilizing a modified emulsion-solvent evaporation technique and using cellulose propionate and ethyl cellulose as polymers. The release rate of the drug from the prepared microspheres was markedly retarded when compared with the commercial theophylline capsules (Theo SR 100). Moreover, ethyl cellulose as a polymer shows a more retarded effect of the drug release.

\section{REFERENCES}

1- A. Kamyshny and S. Magdassi, "Encyclopaedia of Surface and Colloid Science", edited by Hubbard, A., $1^{\text {st }}$ Ed., Marcel
Dekker Inc., New York, Basel, 2004, p. 1.

2- P. B. Deasy, "Microencapsulation and Related Drug Processes", Marcel Dekker Inc., New York, and Basel, 1984, p. 21.

3- E. Tomlinson, Int. J. Pharm. Technol. Prod. Mfr., 4, 49 (1983).

4- L. R. Beck, D. R. Cowsar, D. H. Lewis, R. J. Cosgrove, C. T. Riddle, S. L. Lowry and $\mathrm{T}$. Epperly, Fertility Sterility, 31, 545 (1979).

5- F. Koosha, R. H. Muller, S. S. Davis and M. C. Davies, J. Control. Rel., 9, 149, (1989).

6- R. Bodmeier and J. W. McGinity, Int. J. Pharm., 43, 179 (1988). 
7- P. J. Watts, M. C. Davies and C. D. Melia, Crit. Rev. Therap. Drug Carrier Syst., 7, 235 (1990).

8- P. B. O'Donnell and J. W. McGinity, Advanced Drug Delivery Reviews, 28, 25 (1997).

9- W. M. Obeidat and J. C. Price, J. Microencap., 20, 1, 57 (2003).

10- A. Gonzālez-Ganza, S. Anguiano-Igea, F. J. OteroEspinar and J. Mēndez, European J. Pharma. and Biopharm., 48, 149 (1999).

11- N. Sinchaipanid, P. Chitropas and A. Miterevej, Pharmaceu. Develop. and Technol., 9, 163 (2004).

12- M. Efentakis and A. Koutlis, Pharma. Dev. Technol., 6, 91 (2001).

13- A. Sandberg, B. Abrahamsson, A. Svenheden, B. Olofsson and R. Bergstrand, Pharm. Res., 10, 28 (1993).

14- T. Hayashi, H. Kanbe, M. Okada, M. Suzuki, Y. Ikeda, Y. Onuki, T. Kaneko and T. Sonobe, Int. J. Pharm., 304, 91 (2005).

15- M. A. Bayomi, S. A. AlSuwayeh and A. El-Helw, Drug Dev. Ind. Pharm., 27, 499 (2001).

16- S. P. Vyas, A. Sood, P. Venugopalan and N.Venkatesan, J. Microencap., 17, 767 (2000).
17- A. G. Gilman, T. W. Rall,, A. S. Nies and P. Taylor, "Goodman and Gilman's The Pharmacological Basis of Therapeutics", $9^{\text {th }}$ Ed., New York: Pergamon Press, 1997, p. 673.

18- V. H. K. Li, J. R. Robinson and V. H. L Lee, "Controlled Drug Delivery: Fundamentals and Applications", edited by J. R. Robinson and V. H. L. Lee, $2^{\text {nd }}$ Ed., New York: Marcel Dekker, 1987, p. 3.

19- Y. Pongpaibul, K. Maruyama and M. Iwatsuru, J. Pharm. Pharmacol., 40, 530 (1988).

20- A. J. Shulka and J. C. Price, Pharm. Res., 6, 418 (1989).

21- Y. Miyazaki, S. Yakou, T. Nagai and K. Takayama, Drug Dev. Ind. Pharm., 29, 795 (2003).

22- N. Noureddine, N. Zerouk, I. Nicolis, P. Allain, S. Sfar and J. Chaumeil, ibid., 31, 397 (2005).

23- W. M. Obeidat and J. C. Price, J. Microencap., 23, 195 (2006).

24- F. A. Mohammed and M. A. Hassan, S.T.P. Pharma Sciences, 13, 319 (2003).

25- P. L. Ritger and N. A. Peppas, J. Control. Rel., 5, 23 (1987).

26- P. L. Ritger and N. A. Peppas, ibid, 5, 37 (1987). 